\title{
O PAPEL DO ENFERMEIRO OBSTETRA NO PROCESSO DE PARTURIÇÃO
}

The role of the nurse midwife in the process of parturition

Nilda Figueiredo Corrêa ${ }^{1}$, Rosilda Lopes de Souza ${ }^{1}$, Gabriela Soares Souza Dias ${ }^{1}$, Ioná Vieira Bez Birolo ${ }^{1}$, Mônica Dal Pont Bonfanti ${ }^{1}$

${ }^{1}$ Curso de Enfermagem - Universidade do Extremo Sul Catarinense - UNESC Criciúma - SC - Brasil

\section{Endereço para correspondência:}

Nilda Figueiredo Corrêa

Rua Almirante Barroso, 150. Ap. 402.

Ed. Piemonte. Comerciário.

Criciuma-SC. CEP: $88.802-250$

Email: nilda_correa@hotmail.com 


\title{
Resumo
}

Pesquisa de abordagem qualitativa, descritiva e de campo, com objetivo geral de identificar o papel do enfermeiro obstetra no processo de parturição. A pesquisa foi realizada com cinco profissionais no Centro Obstétrico e Maternidade de um Hospital da Região Sul de Santa Catarina. Os dados foram coletados com entrevista semiestruturada e observação sistemática e analisados por meio da técnica de análise de conteúdo com categorização, com ordenação, classificação e análise dos dados pesquisados. Os resultados apontaram que as enfermeiras obstetras tem papel fundamental durante o trabalho de parto, acompanhando este processo. Reconhece que a parturiente necessita de uma assistência qualificada que possibilite a realização de cuidados visando um parto humanizado.

Palavras-chave: Maternidade; Parto humanizado; Enfermeiro.

\begin{abstract}
Qualitative research, descriptive and field, with the overall objective of identifying the role of the obstetric nurse in the parturition process. The survey was conducted with five professionals in the Obstetric Center and Maternity Hospital of the southern region of Santa Catarina. Data were collected with semi-structured interviews and systematic observation and analyzed by categorizing with content analysis technique, with sorting, classification and analysis of researched data. The results showed that nurses midwives have key role during labor, accompanying this process recognizes that the mother needs a quality care that enables the realization of care aimed at a humanized birth.
\end{abstract}

Keywords: Maternity; Humanized birth; Nurse.

\section{INTRODUÇÃO}

O parto é um evento anunciado e esperado pela gestante e seus familiares, repleto de significados que são (re) construídos dinamicamente na cultura. $O$ trabalho de parto é a última etapa desse evento de grandes proporções físicas, 
psicológicas e culturais. Fisiologicamente, as últimas horas da gravidez são caracterizadas por dores decorrentes das contrações que ocasionam a dilatação do colo uterino e forçam a saída do bebê pelo canal vaginal ${ }^{1}$.

$O$ processo de humanização com profissionais que incentivam o parto humanizado, com resgate do nascimento de forma natural, é incentivado pela Rede Cegonha, inserido na Política Nacional de Humanização, objetiva garantir a todas as brasileiras o atendimento adequado, seguro e humanizado desde a confirmação da gravidez, passando pelo pré-natal e o parto, até os dois primeiros anos de vida do bebê. As transformações corporais acontecem de forma rápida, ao contrário daquelas que ocorrem gradualmente durante os meses de gestação. Sendo assim, todo cuidado obstétrico envolve a compreensão dos sentimentos gerados em decorrência do momento experimentados por ambos, parturientes e profissionais. Portanto, um cuidado humanizado perpassa pela obrigação do cuidar da mulher no momento do trabalho de parto'.

A humanização é a uma aposta ético-estético-política. Ético porque implica a atitude de usuários, gestores e trabalhadores de saúde comprometidos e corresponsáveis. Estética porque acarreta um processo criativo e sensível de produção da saúde e de subjetividades autônomas e protagonistas. Política porque se refere à organização social e institucional das práticas de atenção e gestão na rede do SUS².

Com esta nova concepção e tendência surgiu o interesse de pesquisar a atuação do enfermeiro obstetra desde o processo de gerenciamento da equipe, orientação a gestante e família e ao processo de parto propriamente dito, além do acompanhamento da puérpera no puerpério imediato.

\section{MÉTODOS}

A pesquisa foi qualitativa, descritiva e de campo.

A pesquisa qualitativa trabalha com motivos, crenças, valores e atitudes, 0 que corresponde ao espaço mais profundo das relações, dos processos e dos fenômenos que não podem ser reduzidos a operacionalização de variáveis ${ }^{3}$. 
As pesquisas descritivas têm como objetivo descrever as características de determinada população, fenômeno ou estabelecimento de relações entre variáveis. Uma das características mais significativas está na utilização de técnicas padronizadas de coleta de dados, tais como o questionário e a observação sistemática. Já o estudo de campo estuda um único grupo em termos de sua estrutura social, ressaltando a interação de seus componentes. Assim, tende a utilizar muito mais técnicas de observação do que de interrogação 4 .

Aplicou-se entrevista semiestruturada com 5 profissionais enfermeiras no Centro Obstétrico e Maternidade de um Hospital da Região Sul de Santa Catarina. A entrevista inicia-se com a identificação do sujeito quanto ao sexo e idade, experiência profissional, formação profissional, participação de educação permanente, a compreensão do papel e dificuldades enfrentadas pelo enfermeiro obstetra e quanto à humanização no processo de parturição.

A entrevista é o instrumento mais usado no trabalho de campo. Através dela, o pesquisador busca obter informes contidos na fala dos atores sociais. Ela não significa uma conversa despretensiosa e neutra, uma vez que se insere como meio de coleta dos fatos relatados pelos autores, enquanto sujeito-objeto da pesquisa que vivenciam uma determinada realidade que está sendo focalizada. Suas formas de realização podem ser de natureza individual e/ou coletiva ${ }^{3}$.

$\mathrm{Na}$ observação sistemática da atuação da enfermeira obstetra foi utilizado um instrumento previamente definido pela autora, constando os seguintes itens: gerenciamento e liderança de equipe, autonomia do enfermeiro frente ao processo de parturição, atuação do enfermeiro obstetra no parto, processo de humanização do parto, orientação da gestante, parturiente e puérpera.

Quanto à observação sistemática, de acordo com Queiroz et al ${ }^{5}$.:

Observar significa aplicar atentamente os sentidos a um objeto para dele adquirir um conhecimento claro e preciso. A observação torna-se uma técnica científica a partir do momento em que passa por sistematização, planejamento e controle da objetividade. O pesquisador não está simplesmente olhando o que está acontecendo, mas observando com um olho treinado em busca de certos acontecimentos específicos. A observação ajuda muito o pesquisador e sua maior vantagem está relacionada com a possibilidade de se obter a informação na ocorrência espontânea do fato.

Os dados foram analisados por meio da técnica de categorização proposta por Minayo, que é compreendida em 3 etapas. Na fase exploratória foi organizado o 
material a ser analisado, de acordo com os objetivos e questões de estudos, definindo as unidades de registros, unidades de contextos, trechos significativos e categorias $^{3}$. Realizou-se uma leitura do material, descobrindo orientações para a análise e registrando impressões. $\mathrm{Na}$ fase de exploração do material foi aplicado o que foi definido na etapa anterior, sendo a fase mais longa, havendo necessidade de fazer várias leituras do material. $\mathrm{Na}$ terceira fase, foi realizado o tratamento e interpretação dos resultados, desvendando o conteúdo subjacente, buscando ideologias, tendências e determinações características dos fenômenos que está sendo analisado, sem excluir as informações estatísticas.

Para preservar o sigilo decorrente das entrevistas realizadas, de acordo com as diretrizes e normas regulamentadoras da Resolução ำ 466/12 que envolvem pesquisa com Seres Humanos e Grupos Vulneráveis, utilizou-se a letra "E" para as Enfermeiras, seguido do respectivo número - E1 a E56. O Projeto foi aprovado pelo Comitê de Ética da UNESC - Projeto nำ770998.

\section{RESULTADOS E DISCUSSÃO}

\section{Categoria 1- Caracterização dos Enfermeiros obstetras}

As cinco enfermeiras obstetras são do sexo feminino, com faixa etária entre 26 a 49 anos, atuam como enfermeiras de 1 a 28 anos e como enfermeiras obstetras de 1 mês a 10 anos. Concluíram a especialização de 1 a 13 anos.

Das cinco profissionais entrevistadas, duas relataram que possuem outra especialização, E1 na área da educação e E5 em Metodologia do Ensino. Três profissionais (E2; E3; E4) não possuem outra especialização. Quanto a atualizações em enfermagem obstétrica, nenhuma das enfermeiras está fazendo ou fez tais atualizações, inclusive não participaram de seminários e outros encontros na área obstétrica no último ano.

A atuação e a formação dos enfermeiros obstetras, indubitavelmente, foram transformadas ao longo do tempo, contudo, questões relacionadas à autonomia profissional e à prática colaborativa na assistência à mulher ainda permeiam as discussões científicas e são pontos de pauta constantes em verdadeiros embates entre profissões e instituições diferentes ${ }^{7}$. 


\section{Categoria 2 - Educação permanente dos enfermeiros obstetras atuantes na maternidade e centro obstétrico}

De acordo com as cinco enfermeiras entrevistadas, o hospital não oferece educação permanente para as mesmas, porém elas relataram que compartilham seus conhecimentos participando dos cursos de educação em saúde oferecidos mensalmente para gestantes na instituição pesquisada.

No âmbito das políticas nacionais de saúde, a educação permanente apresenta-se como uma proposta de ação estratégica capaz de contribuir para a transformação dos processos formativos, das práticas pedagógicas assistenciais e para a organização dos serviços, empreendendo um trabalho articulado entre o sistema de saúde, em suas várias esferas, gestões e instituições formadoras ${ }^{8}$.

A instituição pesquisada oferece para as gestantes do município, acompanhadas no pré-natal tanto em âmbito privado como público, a oportunidade de participar do curso para gestantes que acontece mensalmente, abordando diferentes temas com a participação da equipe multiprofissional (Psicólogo, Enfermeiro Obstetra, Médico Obstetra, Profissional de Educação Física e Médico Pediatra).

\section{Categoria 3 - Papel do enfermeiro obstetra no processo de parturição}

Quando as enfermeiras obstetras foram questionadas sobre o papel que desempenham no processo de parturição, todas as cinco profissionais entrevistadas responderam individualmente e cada qual com uma peculiaridade, conforme o relato de suas falas:

"Acompanhar todo trabalho desenvolvido no centro obstétrico, estar presente nas situações que se fizerem necessária, a enfermeira obstetra é a primeira pessoa que entra em contato com a criança e a entrega para a mãe, isso me deixa muito feliz." (E1).

"Dar suporte emocional, tirar as dúvidas, avaliar as 
emergências, acompanhar os trabalhos no centro obstétrico." (E2).

"É como se fosse um pivô no processo, oferecendo tudo até o limite da parturição." (E3).

"É importante, pois o enfermeiro tem que incentivar o parto natural durante o período de parturição, mesmo sabendo que poderia já ter sido durante o pré-natal." (E4).

"É um papel muito importante porque a gente acompanha todo o processo." (E5).

O cuidar é essencial durante todo o processo de parto. O reconhecimento das necessidades da parturiente é fundamental, assim como a valorização da humanização na assistência, que implica o respeito pelo direito da mulher de participar das decisões quanto aos cuidados que necessita e reconhece como importantes para o seu bem-estar. A autonomia, individualidade e privacidade são condições imprescindíveis para o cuidado humanizado 9 .

Pode-se perceber neste estudo que a enfermeira obstetra tem papel fundamental durante o processo de parir. Acompanhando este processo, reconhece que a parturiente necessita de uma assistência qualificada, possibilitando cuidados mais humanizados desde o ato de entregar o recém-nascido para a mãe, dar suporte emocional e técnico, até a avaliação de situações de emergência, assim como participar da tomada de decisão da via de parto incentivando o parto vaginal.

O processo de autonomia pressupõe que o profissional enfermeiro e a equipe de enfermagem possam interferir no processo de definição das prioridades na assistência. A autonomia está embasada na direção da vontade do indivíduo para a ação, a partir de influências sociais e culturais ${ }^{5}$.

\section{Categoria 4 - Facilidades do enfermeiro obstetra para o processo de trabalho na maternidade e centro obstétrico do hospital}

Quando questionado sobre as facilidades do enfermeiro obstetra para o processo de trabalho no Centro Obstétrico, foram relacionadas ao ambiente humanizado, autonomia para o trabalho com a parturiente, ter um enfermeiro 
obstetra nas $24 \mathrm{~h}$ e poder oferecer conforto sem tratamento farmacológico, como ilustram as falas a seguir:

"Ambiente humanizado, autonomia para o trabalho com a parturiente, por parte da instituição." (E1).

"Ter sempre um enfermeiro obstetra presente nas $24 \mathrm{~h}$ do dia, ter autonomia para intervir inclusive na evolução e colocar em prática o que se aprendeu sobre humanização." (E2).

"Autonomia para o processo". (E3).

"Oferecer conforto sem tratamento farmacológico." (E4).

"Ter apoio da direção, da coordenação, autonomia para desenvolver o serviço." (E5).

Ao analisar as falas, percebe-se que as facilidades do trabalho do enfermeiro obstetra estão relacionadas à presença do mesmo nas 24 horas de funcionamento de um centro obstétrico, assim como a autonomia conferida pela instituição para a tomada de decisão durante o processo de parturição.

Pode-se perceber neste estudo que todas as enfermeiras obstetras possuem autonomia no momento dos partos sem riscos e, geralmente, possuem credibilidade da equipe médica em relação à conduta que devem adotar. As participantes consideram a autonomia imprescindível para o cuidado integral prestado pelo enfermeiro obstetra durante o período gravídico puerperal. Para fortalecer esta autonomia faz-se necessário o apoio de toda a equipe, o que proporcionará uma assistência com qualidade e estabelecerá uma relação de ajuda e confiança.

O tema da autonomia do profissional enfermeiro no processo de cuidar no contexto hospitalar torna-se a cada dia mais importante, pois proporciona a possibilidade de rever a enfermagem, enquanto profissão, a partir de sua própria tradição histórica, que é o cuidar, bem como articulando com outras áreas científicas, em um exercício moderno de interdisciplinaridade ${ }^{5}$. 
Categoria 5 - Dificuldades do enfermeiro obstetra para o processo de trabalho na maternidade e centro obstétrico

Da mesma forma, as dificuldades que o enfermeiro obstetra enfrenta frente ao processo de trabalho foram citadas pelas cinco profissionais que relataram haver ainda resistência de alguns profissionais médicos. As falas de algumas delas sugerem que:

"Alguns médicos ainda são resistentes." (E1).

"Alguns profissionais médicos ainda são resistentes, principalmente quanto ao parto humanizado na banheira.” (E2). "Há resistência de alguns médicos e que sempre tem que ter um jeitinho para falar." (E4).

Dificuldades podem permear a vida profissional e estas geralmente fazem parte do contexto em que a conduta profissional está inserida. Após período de institucionalização do parto, o retorno para uma prática diferenciada que favoreça a naturalidade do processo de parturição pode encontrar resistência dos profissionais que estão diretamente envolvidos nesta assistência.

\section{Categoria 6 - Processo de parturição deste hospital é humanizado?}

Em relação ao processo humanizado de parturição do hospital, todas as profissionais responderam sim, o processo é humanizado. Em uma das falas a profissional manifestou-se da seguinte forma:

"A gente tenta fazer o mais humanizado possível." (E4).

A parturição é um dos momentos em que a mulher mais necessita de apoio emocional. Quando este processo é realizado por profissionais e instituição que valorizam esse cuidado, a relação entre os envolvidos se fortalece. Ficou claro neste estudo que as enfermeiras obstetras consideram o trabalho de parto humanizado, porém com a fala de E4 podemos perceber que outras possibilidades de 
Artigo Original

Atenção à Saúde

humanização da parturição podem ser desenvolvidas.

\section{Categoria 7 - Processo de humanização do parto com a atuação do enfermeiro obstetra}

Em relação ao questionamento sobre a forma como ocorre o processo de humanização do parto, cada uma das profissionais respondeu conforme ilustram as falas a seguir:

"Através dos grupos de gestantes, com a presença do acompanhante, com diálogo, banho terapêutico, bola, musicoterapia." (E1).

"Através do banho terapêutico, bola, com a presença do acompanhante, doula, massagens, alimentos, escolha da posição para o parto.” (E2).

"Oferecer conforto, acompanhantes, posição livre para o tipo do parto, banho terapêutico, bola, alimentação." (E3).

O relacionamento entre paciente e profissional e instituição é fundamental para o processo de humanização, sendo este composto por fatores como comunicação, empatia, conhecimentos técnico-científicos e respeito pelos seres humanos ${ }^{10}$.

\section{Categoria 8 - Orientações para as parturientes realizadas pela enfermeira obstetra durante o processo de parturição}

Este estudo mostrou que todas as enfermeiras entrevistadas proporcionam conforto desde os grupos de gestantes até o momento da parturição, com banho terapêutico, relação dialógica, exercício na bola, alimentação, acompanhante, doula, massagens terapêuticas, musicoterapia, posição livre para o tipo de parto, e todo apoio emocional que necessitar, considerando estas possibilidades como ferramentas para a humanização do processo de parto e inclusive no puerpério, como se pode constatar nas falas a seguir: 
“Tranquilizá-las, deixá-las o mais confortável possível, oferecer todas as técnicas e orientações necessárias para que o parto ocorra da melhor maneira possível." (E1).

"Explicar sobre a melhor forma de trazer seu bebê ao mundo, prepará-la para as contrações, oferecer técnicas de ajuda para o conforto, estar tranquila e pensar positivo." (E2).

"Acalmá-la, ensinar técnicas de respiração, orientar sobre todos os passos importantes." (E3).

"Oferecer banho terapêutico, caminhar, oferecer posição que melhor se adaptar." (E4).

"Caminhar, orientar o acompanhante a dar apoio, orientar em como participar do processo do parto." (E5).

Diante das falas acima, todos os enfermeiros entrevistados oferecem conforto para que o parto ocorra da melhor maneira possível, preparando a parturiente para o momento das contrações, orientando a caminhar, ao banho terapêutico, a forma de respirar e a posição que melhor se adaptarem para o alívio da dor.

Percebeu-se, ainda, durante a observação realizada no serviço, tanto dentro do centro obstétrico como na maternidade, que todas as enfermeiras entrevistadas orientam com clareza e tranquilidade as gestantes, parturientes e puérperas. As orientações estão relacionadas à amamentação exclusiva e à livre demanda no peito até o sexto mês, ferida operatória (cesárea ou episiotomia), cuidados com a higiene corporal (da mãe e do bebê), ingurgitamento da mama, cuidados com o RN, retorno a atividade sexual, planejamento familiar e outros temas que são compartilhados com todas as puérperas por todas as entrevistadas. As orientações são registradas no sistema de prontuário eletrônico da instituição. 


\section{Categoria 9 - Gerenciamento e liderança de equipe}

Pode-se observar um bom entrosamento entre a enfermeira obstetra e sua equipe, mantendo boa conduta e postura, proporcionando um ambiente harmonizado.

Acreditamos que o gerente pode desenvolver o papel de agente de mudança desde que desenvolva habilidades de liderança, pois apesar da visão atual de uma liderança não centrada em um único indivíduo, é este gerente que é chamado, frequentemente, nas organizações para conduzir este processo ${ }^{11}$.

Nesta mesma perspectiva, foi perguntado sobre a temática do trabalho, e as entrevistadas se manifestaram com as falas que seguem:

"O tema foi muito bem escolhido, pois o enfermeiro obstetra conquistou seu espaço, tem mais autonomia e todo o apoio das instituições." (E1).

"Acredito que o enfermeiro obstetra tem um papel insubstituível durante o processo de parturição. Tem credibilidade, capacidade e conhecimento." (E2).

"Importante, porém ainda não se tem o reconhecimento necessário." (E3).

"Apesar de ainda ser um processo lento, é importante para as parturientes, principalmente pela confiança." (E4).

"É o papel mais importante, principalmente para o acolhimento. Observar as intercorrências durante o processo e poder reverter. É o trabalho de dar a vida." (E5).

De acordo com a fala das entrevistadas, o tema do trabalho foi bem escolhido e acreditam que o enfermeiro obstetra tem um papel primordial durante 0 processo de parturição. Tem credibilidade, capacidade, conhecimento e tem o papel mais importante, que é o acolhimento e acompanhamento do processo de parturição. 


\section{CONCLUSÃO}

Refletindo sobre o contexto geral do tema proposto para este trabalho, buscou-se ampliar o conhecimento sobre o papel do enfermeiro obstetra frente ao processo de parturição através da caracterização e as diversas formas de atuação das mesmas.

As enfermeiras obstetras participantes deste estudo são do sexo feminino, com faixa etária entre 26 a 49 anos, atuam como enfermeiras de 1 a 28 anos e como enfermeiras obstetras de 1 mês a 10 anos. Afirmaram que a instituição não dispõe de educação permanente, mas elas participam de atividades de educação em saúde com gestantes, salientando sobre a importância de acompanhamento periódico e contínuo das gestantes durante o pré-natal realizado em Unidades Básicas de Saúde.

As hipóteses deste estudo foram todas validadas, em que cita-se: no centro obstétrico e maternidade do hospital em estudo se percebeu que as enfermeiras obstetras acompanham a mulher no processo de parturição e puerpério oferecendo orientações adequadas; percebe-se que é fundamental o papel da enfermeira obstetra na humanização do parto, trabalhando para resgatar o nascimento de forma mais natural; neste contexto validou-se também hipótese de que a enfermeira obstetra encontra dificuldades na autonomia para o processo de parturição com a equipe multiprofissional, principalmente em relação ao profissional médico; e ainda que a enfermeira obstetra orienta quanto a importância da tranquilidade da parturiente e seu acompanhante, respiração adequada, manejo das contrações e ao tipo de parto.

Os objetivos propostos foram todos alcançados. Deste modo, podemos afirmar que as facilidades do enfermeiro obstetra para o processo de trabalho no Centro Obstétrico foram relacionadas ao ambiente humanizado, ter um enfermeiro obstetra nas $24 \mathrm{~h}$, poder oferecer conforto sem tratamento farmacológico e autonomia conferida pela instituição para a tomada de decisão durante o processo de parturição - esta mesma autonomia foi citada como dificuldade, quando para exercê-la as enfermeiras obstetras encontram resistência de profissionais da equipe.

As enfermeiras entrevistadas se comprometem com a humanização do processo de parturição, e, para tal, estabelecem relação dialógica e proporcionam 
Artigo Original

Atenção à Saúde

conforto desde os grupos de gestantes até o momento da parturição, com técnicas para o alívio da dor, banho terapêutico, respiração adequada, exercício na bola, caminhada, alimentação adequada, acompanhante de sua escolha, doula, massagens terapêuticas, musicoterapia, preparo da parturiente para o momento das contrações, posição livre para o tipo de parto e apoio emocional quando necessitar, considerando estas possibilidades como ferramentas para a humanização do processo de parto.

Ficou claro neste estudo que as enfermeiras obstetras consideram o trabalho de parto na instituição estudada como humanizado, porém admitem existir outras possibilidades de humanização da parturição que podem ser desenvolvidas.

Pode-se perceber neste estudo que a enfermeira obstetra tem papel fundamental durante o processo de parir. Acompanhando este processo, reconhece que a parturiente necessita de uma assistência qualificada que possibilite, durante esse momento, cuidados mais humanizados desde o ato de entregar o recémnascido para a mãe, dar suporte emocional e técnico, até a avaliação de situações de emergência, assim como participar da tomada de decisão da via de parto incentivando o parto vaginal.

Quanto ao gerenciamento e liderança da equipe, durante o período de permanência no centro obstétrico e maternidade pode-se observar um bom entrosamento entre a enfermeira obstetra e sua equipe, mantendo boa conduta e postura, proporcionando um ambiente harmonizado.

As entrevistadas consideraram o tema do trabalho importante e acreditam que a enfermeira obstetra, como coadjuvante, tem um papel fundamental durante 0 processo de parturição. Tem credibilidade, capacidade, conhecimento, e tem o papel mais importante, que é o acolhimento e acompanhamento do processo de parturição. Por isso consideramos importante que outras pesquisas sejam realizadas nesta área.

\section{REFERÊNCIAS}

1. Dias MAB, Deslandes SF. Expectativas sobre a assistência ao parto de mulheres usuárias de uma maternidade pública do Rio de Janeiro, Brasil: os desafios de uma política pública de humanização da assistência. Cad Saúde Pública. 2006;22(12):2647-55. 
2. Brasil. HumanizaSUS: documento base para gestores e trabalhadores do SUS. In: Saúde Md, editor.: Ministério da Saúde Brasília (DF); 2008.

3. Neto OC, Gomes R, Minayo MC. Pesquisa social: teoria, método e criatividade. Petrópolis, RJ: Editora Vozes. 1999.

4. Gil AC. Métodos e Técnicas de Pesquisa Social. 6 ed. São Paulo: Atlas; 2008. 89-135 p.

5. Queiroz DT, Vall J, Vieira NFC. Observação participante na pesquisa qualitativa: conceitos e aplicações na área da saúde. Rev enferm UERJ. 2007;15(2):276-83.

6. Brasil. Resolução no 466, de 12 de dezembro de 2012. Diário Oficial da União: Conselho Nacional de Saúde.; 2015.

7. Aquino PS, Rogerio RF, Silva SF, Pinheiro AKB, Damasceno AKC. Análise da produção científica sobre enfermagem obstétrica na base de dados Scielo. Rev RENE. 2011;12(1).

8. Jesus MCP, Figueiredo MAG, Reis Santos SM, Amaral AMM, Oliveira Rocha L, Thiollent MJM. Educação permanente em enfermagem em um hospital universitário. Rev Esc Enferm USP. 2011;45(5):1229-36.

9. Pieszak GM, Terra MG, Neves ET, Pimenta LF, Padoin SMdM, Ressel LB. Percepção dos profissionais de enfermagem acerca do cuidar em centro obstétrico. Rev Rene. 2013;14(3).

10. Souza Machado NX, Souza Praça N. Centro de parto normal e assistência obstétrica centrada nas necessidades da parturiente. Rev Esc Enferm USP.

11. Lourenço MR, Shinyashiki GT, Trevizan MA. Gerenciamento e liderança: análise do conhecimento dos enfermeiros gerentes. Rev latinoam enferm. 2005;13(4):469-73. 